\title{
Rancang Bangun Alat Pengering Udang Ebi Tenaga Biomass Di Kecamatan Sungai Kunyit
}

\author{
Junaidi $^{1)}$, Rudi Kurnianto ${ }^{2)}$ \\ ${ }^{1,2)}$ Program Studi Teknik Elektro Jurusan Teknik Elektro \\ Fakultas Teknik, Universitas Tanjungpura \\ e-mail : juntek@ymail.com ${ }^{1)}$, rudikuru@gmail.com ${ }^{2)}$
}

\begin{abstract}
Most of the people in the district of Sungai Kunyit are engaged in the business of seafood including udang ebi. Udang ebi's monthly production in this district reached $5000 \mathrm{~kg}$. Although the potential of udang ebi processing in Sungai Kunyit dsitrict is quite large, it's benefits still not improve the lives and welfare of the local fishermen. The low of education level may directly affect welfare of society that in general are still categorized as underprivileged families. Partners in this community service activities are the drying group of udang ebi in the territory of Sungai Kunyit district. The partners were Usaha Bahari Terpadu and Karya Bersama. These drying groups of udang ebi are generally running their business still use the traditional way by relying on the natural sunlight for drying udang ebi catches. So that during the rainy season, where the sun shines not too good and often cloudy, their income declined up to $40 \%$. The above problem encouraged the team Community Services in the Sungai Kunyit district to conduct socialization and pilot project in construction drying oven for udang-ebi. Through this science and technology for Society (Ibm) program funded by Directorate of Research and Community Service (DP2M), it is expected to give significant effect on improvement in live and welfare of the local fishermen, especially drying group of udang-ebi, and finally increases the health, education and economic levels of society in general.
\end{abstract}

Keywords-Nelayan, Ebi, Mesin pengering, Biomass.

\section{Pendahuluan}

Kecamatan Sungai Kunyit adalah salah satu kecamatan di Kabupaten Mempawah, memiliki luas wilayah $153,12 \mathrm{Km} 2$, dengan jumlah penduduk 22.224 jiwa dan dikarenakan desa-desa diwilayah kecamatan ini berada di pesisir atau tepi pantai Laut Natuna maka sebagian besar penduduknya bekerja sebagai nelayan. Kehidupan nelayan sangat bergantung kepada musim, apabila musim kemarau mereka mendapatkan hasil laut berupa udang dan ikan untuk dijual atau diolah menjadi udang ebi dan ikan asin atau berbagai jenis pengolahan lainnya. Akan tetapi apabila musim hujan gelombang tinggi, mereka tidak berpenghasilan. Penduduk di kecamatan Sungai Kunyit masih banyak yang berada dibawah garis kemiskinan, dan sebagian besar diantaranya adalah penduduk pra sejahtera. Data kemiskinan dan keluarga pra sejahtera dapat dilihat dari Tabel 1.

Sebagian besar masyarakat di kecamatan Sungai Kunyit bergerak di bidang usaha hasil laut termasuk udang ebi. Udang ebi adalah udang kecil yang diawetkan dengan cara dikeringkan, banyak digunakan sebagai bumbu masakan atau campuran racikan sayuran. Menjadi penambah kelezatan masakan. Berdasarkan data dari Dinas perikanan Kabupaten Mempawah, masyarakat nelayan kecamatan Sungai Kunyit setiap bulan mampu memproduksi $5000 \mathrm{~kg}$ udang ebi seperti pada Tabel 2.

Tabel 1 Data Keluarga Miskin dan Pra sejahtera Kec. Sungai Kunyit

\begin{tabular}{ccc}
\hline No & KETERANGAN & JUMLAH (Jiwa) \\
\hline 1. & Jumlah KK Keluarga Miskin & 5.723 \\
\hline 2. & Jumlah Penduduk Miskin & 25.201 \\
\hline 3. & Keluarga Pra Sejahtera & 2.327 \\
\hline 4. & Keluarga Sejahtera I & 4.211 \\
\hline 5. & Keluarga Sejahtera II & 3.103 \\
\hline 6. & Keluarga Sejahtera III & 1.946 \\
\hline 7. & Keluarga Sejahtera Pilus & 739 \\
\hline
\end{tabular}

Sumber: Dinas Perikanan dan Kelautan Mempawah

Tabel 2 Pengolahan, Penampungan dan Pemasaran Hasil Perikanan Kec. Sungai Kunyit Kab. Mempawah Tahun 2011

\begin{tabular}{llc}
\hline \multicolumn{1}{c}{ Alamat } & \multicolumn{1}{c}{$\begin{array}{c}\text { Jenis } \\
\text { Produksi }\end{array}$} & $\begin{array}{c}\text { Produksi } \\
\text { per-bulan } \\
(\mathbf{k g})\end{array}$ \\
\hline $\begin{array}{l}\text { Sungai } \\
\text { Kunyit Laut }\end{array}$ & Udang Ebi & 5.000 \\
\hline Semudun & Kerupuk Ikan & 500 \\
\hline Semudun & $\begin{array}{l}\text { Pemasaran } \\
\text { Ikan }\end{array}$ & 3.000 \\
\hline Mendalok & Penampung & 5.000 \\
\hline
\end{tabular}

Sumber: Dinas Perikanan dan Kelautan Mempawah

Dilihat dari besarnya potensi pengolahan udang ebi di di kecamatan Sungai Kunyit, karena sekilonya udang ebi dihargai Rp. 110.000 tetapi keuntungan yang diperoleh dirasakan belum meningkatkan taraf hidup dan kesejahteraan masyarakat kelompok usaha pengolahan udang ebi setempat. Seperti karakteristik masyarakat pesisir pada umumnya adalah tingkat 
pendidikan yang rendah yang secara langsung berpengaruh terhadap tingkat kesejahteraan masyarakatnya yang pada umumnya masih tergolong sebagai keluarga prasejahtera. Mitra pada kegiatan pengabdian pada masyarakat IbM adalah kelompok usaha pengolahan udang ebi di kecamatan Sungai Kunyit. Mitra pertama adalah kelompok Usaha pengolahan udang ebi Bahari Terpadu yang diketuai oleh Rusdi, beanggotakan 12 orang, dengan tingkat pendidikan anggot mayoritas tamat SD dan SMP, beralamat di desa Sungai Kunyit Laut kecamatan Sungai Kunyit. Mitra kedua adalah kelompok usaha pengolahan udang ebi Karya Bersama yang diketuai Ronain, beranggotakan 11 orang, mayotiras tamatan smp, beralamat di desa Sungai Kunyir kecamatan Sungai Kunyit. Kelompok usaha Bahari Terpadu telah berdiri sejak 20 tahun yang lalu, sementara kelompok usaha Karya Bersama berdiri pada tahun 2003.

Kelompok-kelompok usaha pengolahan udang ebi ini menjalankan usahanya masih menggunakan cara tradisional dengan menggantungkan diri pada alam yaitu sinar matahari dalam mengeringkan udang ebi hasil tangkapan. Pada waktu musim kemarau, dimana matahari berlimpah dan tidak ada awan yang menutup matahari, usaha pengeringan mereka berjalan dengan baik. Udang ebi yang dijemur akan kering sesuai dengan tingkat kekeringan tertentu yang diinginkan pasar setelah berhari-hari di jemur. Akan tetapi pada musim penghujan, dimana matahari bersinar tidak terlalu baik dan sering terjadi mendung, pendapatan mereka menurun drastis hingga $40 \%$.

Permasalahan di atas melatarbelakangi tim pelaksana kegiatan Pengabdian Kepada Masyarakat di kelurahan Sungai Kunyit untuk mengadakan sosialisasi dan percontohan dalam pembuatan alat pengering udang ebi tenaga biomass dengan memanfaatkan potensi daerah yang tersedia. Melalui program Ipteks bagi Masyarakat yang dibiayai oleh direktorat Penelitian dan Pengabdian kepada Masyarakat (DP2M) diharapkan dapat memberikan pengaruh nyata terhadap perbaikan taraf hidup masyarakat kecamatan Sungai Kunyit khususnya kelompok usaha pengolahan udang ebi setempat yang pada akhirnya dapat meningkatkan pendapatan masyarakat, demikian juga dalam hal kesehatan, pendidikan maupun tingkat perekonomian masyarakat secara umum.

\section{Permasalahan Mitra}

Bagia Berdasarkan hasil survey yang telah dilakukan maka dapat dikemukakan permasalahan yang dihadapi kelompok usaha pengolahan udang ebi di kecamatan Sungai Kunyit adalah:

- Produksi pengeringan udang ebi pada umumnya menggunakan cara-cara tradisional sehingga pada musim kemarau memerlukan waktu pengeringan $2 \mathrm{~s} / \mathrm{d}$ 3 hari, namun pada musim hujan memerlukan waktu 5 s/d 6 hari mengakibatkan produksi uang ebi menurun sampai dengan $40 \%$.

- Tingkat pendidikan masih rendah, sebagian besar tamatan SD dan SMP yang berimplikasi rendahnya pengetahuan dan kesadaran untuk menjaga kebersihan dari produk yang dihasilkan.

- Terbatasnya akses bantuan modal usaha untuk pengembangan pengolahan udang ebi bagi kelompok usaha pengeringan udang ebi.

- Keterbatasan sarana dan prasarana pendukung yang menunjang terhadap penanganan hasil produksi tangkapan laut.

Kelompok-kelompok usaha pengolahan udang ebi masih menggunakan cara tradisional dalam mengeringkan udang ebi. Yang mana cara tersebut juga banyak memiliki kekurangan yang dapat merugikan kelompok usaha pengolahan udang ebi setempat. Kekurangan tersebut antara lain : proses pengeringan memakan waktu yang bervariasi tergantung kondisi cuaca, pada saat cuaca cerah penjemuran udang ebi memakan waktu lebih kurang 3 hari; hanya dapat dilakukan di daerah tropis (musim panas), proses pengeringan tidak bisa dikontrol, membutuhkan areal yang luas untuk proses pengeringan, dan faktor kebersihan dari bahan yang dikeringkan sangat kurang karena proses pengeringan dilakukan di tempat terbuka. Yang tentunya sangat rawan terhadap serangan lalat dan terkontaminasi kotoran sehingga dapat mempengaruhi daya simpan udang ebi. Selain itu jika pengeringan dijemur tidak sempurna justru udang ebi mudah busuk karena terkena serangan jamur, belatung dan kutu. Sebaliknya, bila cuaca terlalu panas, pengeringan berlangsung terlalu cepat sehingga dapat terjadi case hardening yaitu permukaan daging udang ebi mengeras.

\section{Metode Pelaksanaan}

Kegiatan ini dilaksanakan di daerah Sungai Kunyit Kecamatan Sungai Kunyit Kabupaten Mempawah. Kegiatan ini juga melibatkan dan kerjasama yang baik dari tim pelaksana dan kelompok masyarakat khususnya kelompok usaha pengolahan udang ebi. Tim pelaksana secara garis besar memberikan arahan dalam pembuatan unit pengering udang ebi tenaga biomass dengan memanfaatkan potensi udang ebi yang tersedia, juga memanfaatkan limbah terbuang yang banyak terdapat di kecamatan Sungai Kunyit seperti tempurung kelapa dan sekam padi. Tim pelaksana juga dibantu oleh tim PPL (Petugas Pembantu Lapangan) dari Dinas Perikanan dan Kelautan Kabupaten Mempawah. Sebagai mitra pada kegiatan pengabdian pada masyarakat IbM adalah kelompok usaha pengolahan udang ebi di kecamatan Sungai Kunyit. Mitra pertama adalah kelompok Usaha pengolahan udang ebi Bahari Terpadu yang diketuai oleh Rusdi, beanggotakan 12 orang, dengan tingkat pendidikan anggot mayoritas tamat SD dan SMP, beralamat di desa Sungai Kunyit Laut kecamatan Sungai Kunyit. Mitra kedua adalah kelompok usaha pengolahan udang ebi Karya Bersama yang diketuai Ronain, beranggotakan 11 orang, mayotiras tamatan smp, beralamat di desa Sungai Kunyir kecamatan Sungai Kunyit. Kelompok usaha Bahari Terpadu telah berdiri sejak 20 tahun yang lalu, sementara kelompok usaha Karya Bersama berdiri pada tahun 2003. Kelompok usaha pengolahan udang ebi ini diharapkan dapat 
menjadi Pilot Project bagi kelompok usaha pengolahan udang ebi lainnya. Sebagai mitra kelompok usaha ini bersama pemerintah setempat yang akan menyiapkan lokasi yang nantinya akan digunakan untuk pembuatan mesin/alat pengering udang tenaga biomass.

Pada kegiatan IbM ini dibuat rancang bangun Mesin Pengering Udang Ebi Tenaga Biomassa. Mesin pengering ini terdiri dari rak pengering dan blower.

Tabel 3 Bahan-bahan yang diperlukan

\begin{tabular}{|c|l|l|}
\hline No & \multicolumn{1}{|c|}{ Nama Bahan } & \multicolumn{1}{|c|}{ Jumlah } \\
\hline 1 & Motor Listrik & 1 unit \\
\hline 2 & Steel Plat $2 \mathrm{~mm}$ & 7 Keping \\
\hline 3 & Besi Siku $3 \times$ x $\mathrm{cm}$ & 6 batang \\
\hline 4 & Elbow Pipa & 2 buah \\
\hline 5 & $\begin{array}{l}\text { Plat Garmis } \propto 5 \mathrm{~mm}, \mathrm{~T} \\
=3 \mathrm{~mm}\end{array}$ & 5 Keping \\
\hline 6 & Besi Shaft $\propto 10 \mathrm{~mm}$ & 1 buah \\
\hline 7 & Engsel Pintu & 4 buah \\
\hline 8 & Besi Hollow 4 x $4 \mathrm{~cm}$ & 1 Batang \\
\hline 9 & Semen anti api & 1 Karung \\
\hline 10 & Mur + Baut M4 & 30 buah \\
\hline 11 & Mur + Baut M10 & 10 buah \\
\hline 12 & kopling & 1 Pasang \\
\hline 13 & Blower & 1 buah \\
\hline 14 & Kabel Listrik & 10 meter \\
\hline 15 & Steker & 1 buah \\
\hline
\end{tabular}

Dimensi model seluruh mesin yang akan dibuat ruang pengering: panjang $180 \mathrm{~cm}$, lebar $74 \mathrm{~cm}$, tinggi 80 $\mathrm{cm}$. Dimensi ruang pengeringan panjang $126 \mathrm{~cm}$, lebar $54 \mathrm{~cm}$ dan tinggi $80 \mathrm{~cm}$. Jumlah rak pengeringan sebanyak 3 rak. Peralatan yang digunakan untuk mengalirkan udara adalah blower $\varnothing 200 \mathrm{~mm}$. Sumber panas didapat dari pembakaran tempurung kelapa, sekam, kayu bakar dll. Sumber penggerak untuk memutar impeller di blower adalah motor listrik. Udara yang dihasilkan oleh pembakaran bahan bakar dialirkan ke dalam ruang utama mesin guna untuk mengeringkan udang ebi, dan udara panas yang tersisa akan dialirkan melalui cerobong yang terdapat di atas mesin (ruang pengering) sehingga akan terdapat aliran udara panas di dalam ruang pengeringan. Cara Kerja Mesin Pengering Udang Ebi Tenaga Biomassa yang dibuat pada kegiatan IbM ini adalah sebagai berikut:

- Sebelum melaksanakan proses pengeringan udang ebi, bersihkan dulu udang ebi tersebut dari kotorankotoran.

- Letakkan udang ebi yang basah di atas plat yang di sediakan dan hampar udang tersebut di atas plat secara merata.

- Masukan udang ebi yang ada diatas plat kedalam rak mesin pengering dan rapikan, tutup pintu mesing pengering.

- Siapkan bahan sumber panas yang akan di gunakan untuk pergering, bahan tersebut contohnya: tempurung kelapa, sekam, briket, kayu bakar, dll, bahan tersebut di bakar di dalam tempat yang sudah disediakan.

- Setelah bahan bakar tersebut terbakar dan menghasilkan panas yang di butuhkan selanjutnya hidupkan motor listrik yang mengerakkan boiler, boiler tersebut berfungsi untuk menghisap panas yang di hasilkan bahan bakar dan di alirkan kedalam ruangan mesin pengering.

- Pada saat proses pengeringan yang harus selalu di perhatikan adalah bahan sumber panas harus selalu di cek agar tidak habis dan udang ebi yang terdapat di dalam mesin pengering di cek agar bila sudah kering lakukan pengantian dengan rak yang terdapat udang ebi yang masih basah.

- Lakukan proses tersebut secara berkala.

- Untuk mematikan mesin pengering ini yang pertama di lakukan adalah mematikan bahan bakar yang di bakar hingga tidak adanya sisa api yang menyala, kemudian matikan motor listrik. Keluarkan sisa udang ebi yang di keringkan.Kemudian bersihkan mesin tersebut.

Sebelum udang ebi dikeringkan menggunakan Mesin Pengering Udang Ebi Tenaga Biomassa ini, terlebih dahulu diperlukan persiapan awal sebagai berikut:

- Kupas kulit udang dan buang kotorannya.

- Cuci udang ebi dengan air bersih (sebaiknya yang mengalir), agar semua kotoran yang masih melekat dapat terbuang.

- Untuk meniriskan air dari udang ebi, susun udang ebi pada wadah berongga.

- Setelah agak kering, timbang berat udang ebi guna menghitung jumlah garam yangdibutuhkan untuk proses penggaraman.

- Selanjutnya dilakukan proses pengeringan dengan menggunakan alat pengering udang ebi yang telah dibuat.

Rancang bangun Mesin Pengering Udang Ebi Tenaga Biomass diperlihatkan pada Gambar 1.

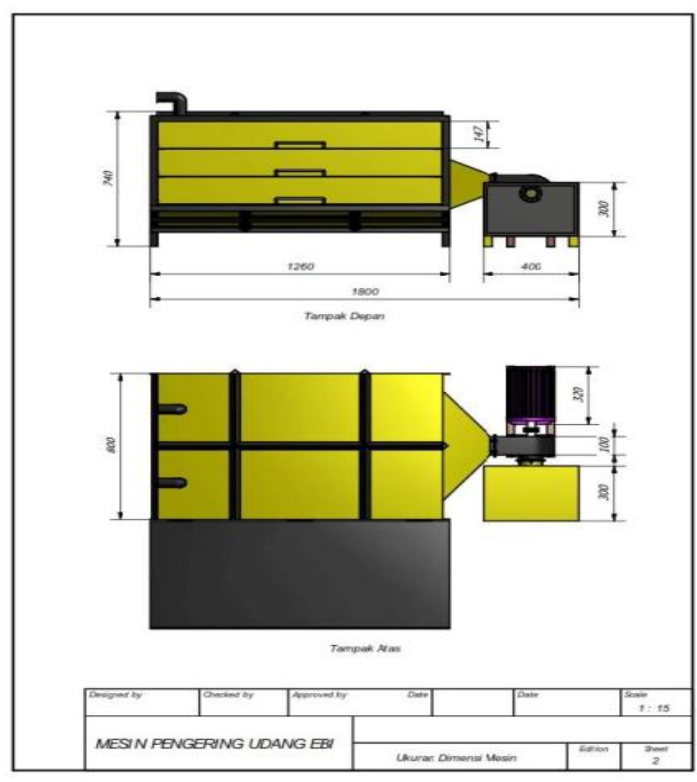

(a) 


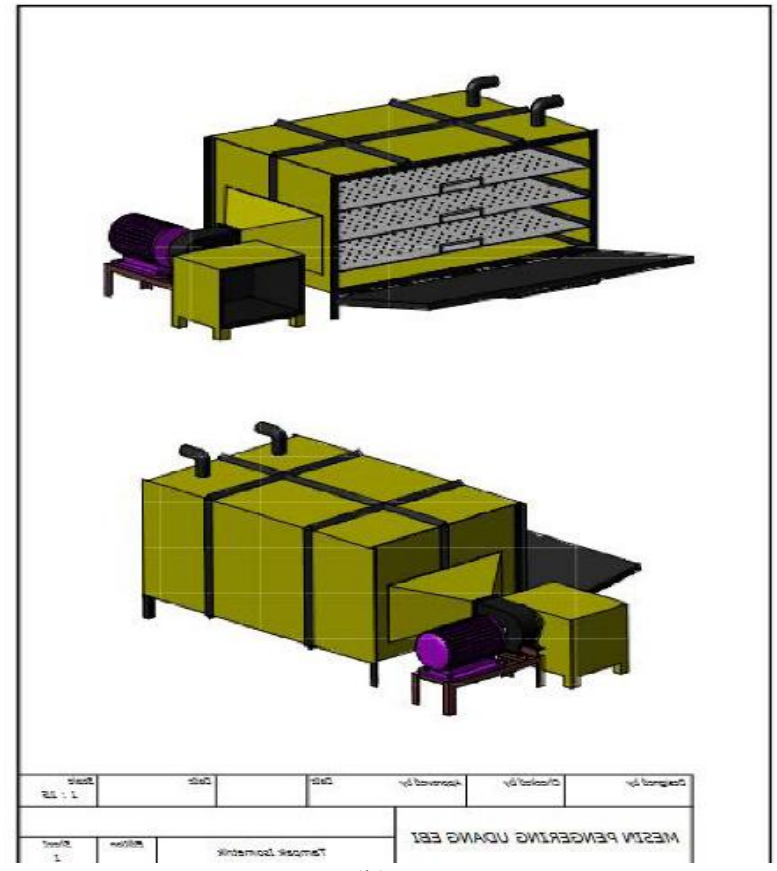

(b)

Gambar 1 Mesin Pengering Udang Ebi Tenaga Biomass (a) Tampak samping; (b)Tampak atas

Strategi pemasaran diberikan kepada kelompok usaha pengolahan udang ebi dengan memberikan data dan informasi tentang peluang pemasaran produksi udang ebi, menjamin mutu udang ebi dan menjaga ketersediaan produk udang ebi. Juga mengefektifkan promosi langsung kepada konsumen untuk memperkenalkan produk dari kelompok usaha pengolahan udang ebi, juga menjadikannya sebagai ciri khas buah tangan dari kecamatan Sungai Kunyit kabupaten Mempawah.

\section{Luaran Kegiatan}

Bagian Hasil yang telah dicapai oleh tim pelaksana IbM adalah sebagai berikut:

- Menyelesaikan pembuatan instalasi unit Teknologi Tepat Guna (TTG) Mesin Pengering Udang Ebi Tenaga Biomassa sesuai spesifikasi usulan pada proposal;

- Mesin Pengering Udang Ebi Tenaga Biomassa yang sudah jadi di serahkan kepada kelompok mitra di sungai kunyit;

- Melakukan pengujian unit instalasi TTG Mesin Pengering Udang Ebi Tenaga Biomassa dan berhasil dengan baik, sesuai dengan tujuan yang diinginkan; Melakukan sosialisasi langsung kepada masyarakat, tokoh masyarakat dan instansi yang terkait;

- Cara penggunaan TTG Mesin Pengering Udang Ebi Tenaga Biomassa, beserta cara pemeliharaan dan perawatannya.

Produk luaran dari kegiatan ini berupa sebuah percontohan Mesin Pengering Udang Ebi Tenaga Biomassa sebagaimana diperlihatkan pada Gambar 2.

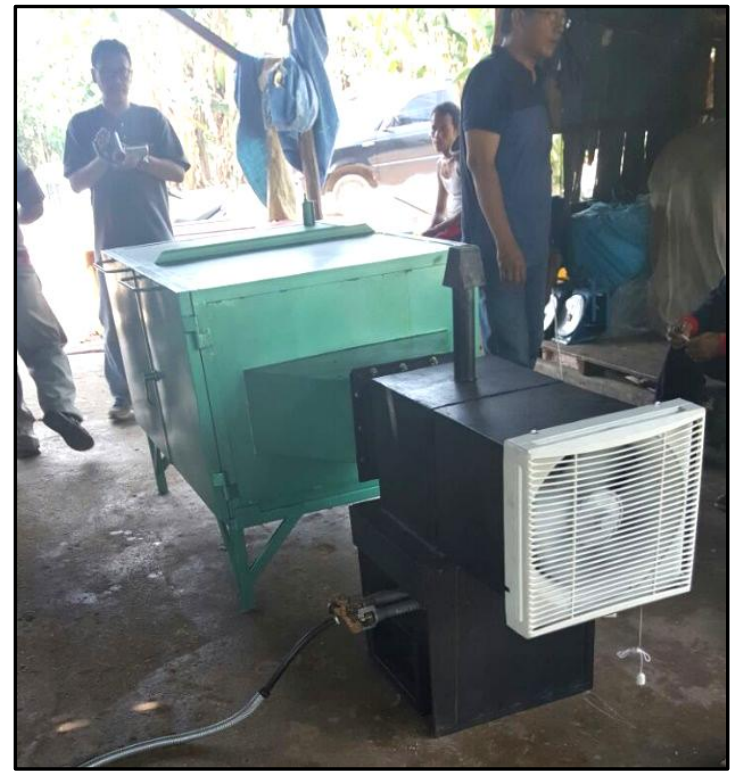

(a)

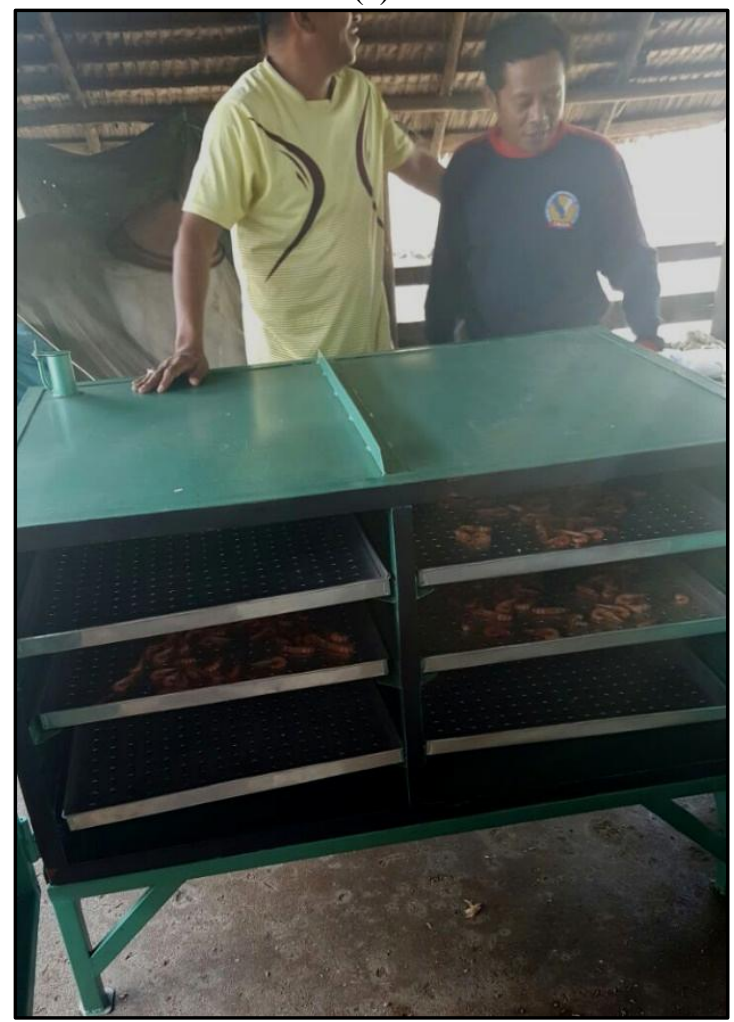

(b)

Gambar 2 .a \& b Mesin Pengering Udang Ebi Tenaga Biomass

Dengan adanya sosialisasi ini diharapkan masyakat paham tentang tata cara penggunaan dan pemeliharaan alat tersebut sehingga penggunaan alat tersebut dapat berlangsung dalam jangka yang panjang. Memetakan potensi konsumen udang ebi sebagai strategi pemasaran dan kelangsungan usaha selanjutnya. 


\section{Kesimpulan}

Kegiatan Sebagian besar masyarakat di kecamatan Sungai Kunyit bergerak di bidang usaha hasil laut termasuk udang ebi. Produksi perbulan udang ebi di kecamatan Sungai Kunyit mencapai $5000 \mathrm{~kg}$. Dilihat dari besarnya potensi pengolahan udang ebi di kecamatan Sungai Kunyit tetapi keuntungan yang diperoleh dirasakan belum meningkatkan taraf hidup dan kesejahteraan nelayan setempat. Seperti karakteristik masyarakat pesisir pada umumnya adalah tingkat pendidikan yang rendah yang secara langsung berpengaruh terhadap tingkat kesejahteraan masyarakatnya yang pada umumnya masih tergolong sebagai keluarga prasejahtera. Mitra pada kegiatan pengabdian pada masyarakat IbM adalah kelompok usaha pengeringan udang ebi yang berada di wilayah di kecamatan Sungai Kunyit. Mitra pertama adalah kelompok Usaha Bahari Terpadu dan mitra kedua adalah kelompok usaha Karya Bersama. Kelompok-kelompok usaha pengeringan udang ebi ini pada umumnya menjalankan usahanya masih menggunakan cara tradisional dengan menggantungkan diri pada alam yaitu sinar matahari dalam mengeringkan udang ebi hasil tangkapan. Sehingga pada musim penghujan, dimana matahari bersinar tidak terlalu baik dan sering terjadi mendung, pendapatan mereka menurun drastis hingga $40 \%$. Mesin pengering udang ebi tenaga biomass hasil kegiatan ini memanfaatkan potensi daerah yang tersedia. Melalui program Ipteks bagi Masyarakat yang dibiayai oleh direktorat Penelitian dan Pengabdian kepada Masyarakat (DP2M) telah memberikan pengaruh nyata terhadap perbaikan taraf hidup masyarakat kecamatan Sungai Kunyit khususnya kelompok usaha pengeringan udang ebi setempat, yaitu meningkatkan pendapatan masyarakat, demikian juga dalam hal kesehatan, pendidikan maupun tingkat perekonomian masyarakat secara umum. Strategi pemasaran diberikan kepada kelompok usaha pengolahan udang ebi dengan memberikan data dan informasi tentang peluang pemasaran produksi udang ebi, menjamin mutu udang ebi dan menjaga ketersediaan produk udang ebi. Juga mengefektifkan promosi langsung kepada konsumen untuk memperkenalkan produk dari kelompok usaha pengolahan udang ebi, juga menjadikannya sebagai ciri khas buah tangan dari kecamatan Sungai Kunyit kabupaten Mempawah.

\section{Referensi}

[1] Dinas Perikanan Kabupaten Mempawah, 2012, Data Keragaan Pola Pemanfaatan Hasil Perikanan Kabupaten Pontianak.

[2] Dinas Sosial Tenaga Kerja Dan Transmigrasi Kabupaten Mempawah, 2012, Data KUBE Fakir Miskin Kabupaten Pontianak.

[3] Kecamatan Sungai Kunyit, 2011, Profil Kecamatan Sungai Kunyit Tahun 2011.

[4] Rosdaneli, 2005, Proses Pengeringan, Fakultas Teknik Prodi Teknik Kimia, Medan. 